\title{
Visão comparativa das estratégias climáticas adotadas por multinacionais do setor de alumínio no Canadá e no Brasil
}

\section{A comparative picture of climate strategies adopted by aluminum multinational corporations in Canada and Brazil}

\author{
Larissa Teixeira da Cunha ${ }^{1}$ \\ Mônica Cavalcanti Sá de Abreu ${ }^{1}$ \\ Luciano Barin-Cruz ${ }^{2}$
}

\begin{abstract}
Resumo: O trabalho avalia as estratégias climáticas adotadas por multinacionais do setor de alumínio. A pesquisa adota uma abordagem qualitativa e toma por base entrevistas com gerentes de duas Multinacionais, uma delas instalada no Brasil e a outra no Canadá. As evidências empíricas demonstram que a multinacional do setor de alumínio que opera no Canadá enfatiza a redução de custos e a melhoria da eficiência operacional com projetos para reduzir emissões de gases do efeito estufa. A multinacional que opera no Brasil destaca, prioritariamente, o relacionamento com os stakeholders e a preocupação com a imagem corporativa para a adoção de uma estratégia de adaptação ou compensação das emissões de gases do efeito estufa. Em nenhum dos dois casos estudados, as pressões coercitivas, advindas de exigências regulatórias, figuram como fatores determinantes para a adoção de estratégias climáticas. O estudo conclui que, no caso da indústria de alumínio, características organizacionais são mais relevantes que as pressões institucionais na definição de estratégias climáticas.
\end{abstract}

Palavras-chave: Mudança climática; Estratégia; Desenvolvimento sustentável; Corporações multinacionais; Pressões institucionais; Características organizacionais.

\begin{abstract}
This paper assesses the climate strategies adopted by multinational corporations of the aluminum industry. The research adopted a qualitative approach and was based on interviews with managers from two multinational corporations: one installed in Brazil and the other in Canada. Empirical evidence shows that in order to develop projects to reduce greenhouse gas emissions, the multinational company installed in Canada emphasizes cost reduction and operational efficiency improvement, while the multinational company that operates in Brazil primarily highlights the relationship with stakeholders and the concern with a responsible corporate image. In neither of the two cases studied, coercive pressures arising from regulatory requirements figured as determinant for the adoption of climate strategies. The study concludes that, in the case of the aluminum industry, organizational factors are more relevant than institutional pressures on the definition of climate strategies. Companies may create hedging strategies able to deal with carbon restrictions or attempt to postpone regulations until they have technologies.
\end{abstract}

Keywords: Climate change; Strategy; Sustainable development; Multinational corporations; Institutional pressures; Organizational factors.

\section{Introdução}

As mudanças climáticas representam um grande desafio para a humanidade. Trata-se, indubitavelmente, de um problema de ação internacional coletiva, que implica dificuldades para se estabelecer uma ação coordenada e evitar participações assimétricas dos países. Documentos como o Climate Change (IPCC, 2013), o relatório Pathways to 2050 - Energy

\& Climate Change (WBCSD, 2005) e o Relatório de Impacto Humano (GHF, 2009) relatam os efeitos atuais das mudanças climáticas e traçam perspectivas preocupantes para as próximas décadas. Hoffman (2007) sintetiza que as mudanças climáticas são globais em suas causas, e suas consequências podem se prolongar por um longo período. Portanto, geram

\footnotetext{
${ }^{1}$ Universidade Federal do Ceará - UFC, Av. da Universidade, 2470, CEP 60020-180, Fortaleza, CE, Brasil, e-mail: larissatc@gmail.com; mabreu@ufc.br

${ }^{2}$ École des Hautes Études commerciales de Montréal - HEC Montréal, 3000, Chemin de la Côte-Sainte-Catherine Montréal (Québec) Canada H3T 2A7, e-mail: luciano.barin-cruz@hec.ca
}

Recebido em Jan. 6, 2014 - Aceito em Set. 10, 2014

Suporte financeiro: CNPq, CBIE. 
incertezas que impedem a quantificação precisa de seus impactos econômicos, sociais e ambientais.

O problema das mudanças climáticas exige o desenvolvimento de estratégias empresariais, políticas públicas, mecanismos de mercado e tecnologias inovadores em direção a uma sociedade com baixa emissão de carbono (Rosen, 2007). As incertezas sobre os riscos, as oportunidades, os custos e os benefícios geram debates entre empresas, governos e organizações. A resposta às mudanças climáticas ocorre, portanto, em múltiplas dimensões, envolvendo aspectos políticos, tecnológicos, organizacionais e financeiros.

As corporações multinacionais (MNCs) estão sujeitas a diferentes pressões de stakeholders e atuam em contextos institucionais diversos, levando à adoção de diferentes estratégias climáticas (Kolk \& Van Tulder, 2010). A implementação de decisões estratégicas globais, por parte das MNCs, requer a garantia da transferência de conhecimento, expertise $\mathrm{e}$ ideias em sua rede interorganizacional. A obtenção de vantagens competitivas globais nas MNCs decorre de um desempenho superior da matriz e das subsidiárias (Ellis, 2000).

Em seus papéis de investidores, poluidores, inovadores, experts, produtores, lobistas e empregadores, as MNCs configuram-se como atores centrais na questão da mudança climática (Jones \& Levy, 2007). Para Schultz \& Williamson (2005), o desafio para as empresas consiste em reduzir os custos e os riscos associados, tendo que lidar com a possibilidade de exigências regulatórias de corte nas emissões de gases do efeito estufa (GEE). Nesse debate, Kolk \& Levy (2004) chamam a atenção para o papel do ambiente institucional na capacidade de resposta das MNCs. Os autores afirmam que o contexto do país sede e as características individuais, específicas da firma, ajudam a explicar diferenças existentes entre as estratégias adotadas por empresas pertencentes à mesma indústria.

Este estudo se propõe, portanto, a identificar as similaridades e os contrastes existentes entre as respostas estratégicas de MNCs do setor de alumínio instaladas no Canadá e no Brasil, frente aos desafios das mudanças climáticas. A escolha deste setor justifica-se em virtude da produção de alumínio primário e de alumina emitir uma significativa quantidade de dióxido de carbono $\left(\mathrm{CO}_{2}\right)$, proveniente do consumo dos anodos, e de perfluorcarbonos (PFCs), no caso, os gases tetrafluoreto de carbono $\left(\mathrm{CF}_{4}\right)$ e hexafluoretano $\left(\mathrm{C}_{2} \mathrm{~F}_{6}\right)$, oriundos do processo de redução eletrolítica (Dando et al., 2011). Adicionalmente, os padrões de inovação e desenvolvimento tecnológico da indústria do alumínio são determinados por um restrito número de empresas de grande porte (Fujiwara \& Egenhofer, 2008).
A escolha do Canadá e do Brasil se justifica por apresentarem ambientes institucionais que exercem influências distintas nas estratégias climáticas de MNCs. O Canadá ratificou o Protocolo de Kyoto, que vigorou entre 2008 e 2012, e integrou o Anexo I da Convenção-Quadro das Nações Unidas sobre Mudança do Clima (UNFCCC), se comprometendo a reduzir suas emissões de GEE em 5\% em relação às emissões de 1990. O Brasil também ratificou o protocolo de Kyoto, porém, adotou metas voluntárias de redução de emissões de GEE (Seiffert, 2009).

Freitas et al. (2013) reforçam as incertezas do segundo período do Protocolo de Kyoto, que se iniciou em 2013 e terminará em 2017, com a definição de novas metas obrigatórias de redução de emissões de GEE para os países integrantes do Anexo I. O Canadá, juntamente com os EUA, Japão e Rússia, não ratificou o novo acordo, realizado na Conferência das Partes (COP 18), em Doha, no Qatar, em 2012. Estes países desenvolvidos alegam que países emergentes, como a Índia, China e Brasil, também deveriam ter metas de redução de emissões de GEE a cumprir.

Parte-se da construção de um framework teórico de avaliação de respostas estratégicas e procura-se entender o impacto do ambiente institucional desses dois países (Canadá e Brasil), envolvendo a pressão dos stakeholders e o quadro regulatório sobre mudança climática. Adotam-se também as sugestões de Kolk \& Levy (2004) e de Kolk (2008), as quais atestam como relevantes a avaliação dos fatores associados com as características organizacionais, que envolvem a política ambiental das matrizes, a cultura organizacional, o estágio de desenvolvimento tecnológico, e os custos operacionais associados com as medidas de mitigação e compensação das emissões de GEE.

Para alcançar o objetivo proposto, o artigo está dividido em seções. Na seção seguinte, o referencial teórico explora as forças motrizes e as estratégias empresariais como resposta às mudanças climáticas. Na metodologia, são apresentados os passos para a realização das entrevistas com os gestores de duas multinacionais instaladas no Canadá e no Brasil e, em seguida, são relatados os resultados da pesquisa qualitativa. Estes achados são discutidos à luz do framework teórico desenvolvido e, finalmente, a conclusão reforça o papel do ambiente institucional e das características organizacionais na construção de um modelo empresarial de estratégias climáticas.

\section{Fundamentos conceituais}

\subsection{Forças motrizes e estratégias empresariais como respostas às mudanças climáticas}

Harrison (2009) destaca que as empresas têm voltado sua atenção para as questões de sustentabilidade e as mudanças climáticas. Esta atitude empresarial envolve 
os aspectos econômicos das escolhas no longo prazo e os riscos associados. Lash \& Wellington (2007) definiram seis tipos de riscos relacionados às mudanças climáticas: regulatórios (legislações exigindo a redução de emissões); cadeia de suprimentos (transferência de altos custos relacionados às emissões de carbono pelos fornecedores); produto e tecnologia (desenvolvimento antecipado de produtos e tecnologias ambientalmente mais responsáveis pelos concorrentes); processos legais (por conta de negligência, perturbação da ordem pública ou transgressão); reputação e o risco físico (danos ocasionados ao patrimônio em virtude de eventos climáticos).

Existem fatores que possuem o potencial de forçar as empresas a assumirem ações de resposta às mudanças climáticas, mesmo quando elas normalmente não desejariam fazê-lo. As principais fontes de tais pressões externas são os regulamentos governamentais e as pressões dos stakeholders. Reinhardt (2007) ressalta que as empresas precisam vencer a retórica do ganha-ganha e avançar em direção aos difíceis trade-offs decorrentes da mudança climática.

Nesse sentido, Okereke (2007) defende a transição de preocupações exógenas e periféricas, em direção à incorporação das mudanças climáticas como um aspecto explícito da gestão empresarial estratégica e como um componente endógeno do modelo empresarial. Hoffman \& Woody (2008) afirmam que o período de tempo considerado para se agir deve conter objetivos de curto, médio e longo prazo, além de abarcar mecanismos de mercado necessários para induzir ações e inovações.

A Figura 1 detalha o framework teórico desenvolvido para a definição de uma estratégia climática empresarial, constituída de quatro fases: (1) a identificação dos drivers ou forças motrizes (influência das restrições regulatórias, avanço dos concorrentes e percepção dos stakeholders); (2) o levantamento da exposição ao carbono que trata do estágio atual do inventário das emissões de GEE; (3) os critérios para tomada de ação que envolvem a identificação de ações de compensação e inovação; e (4) a influência das estratégias empresariais sobre o processo político, o qual volta a influenciar os drivers (forças motrizes).

Kolk \& Pinkse (2004) apontam futuras regulações como um dos principais drivers para a redução das emissões de gases de efeito estufa (GEE). Outro driver refere-se ao efeito das mudanças climáticas sobre a capacidade competitiva das empresas, concernente a três aspectos em especial: mudanças nos custos, na demanda, e no desenvolvimento de novas tecnologias. Schultz \& Williamson (2005) mencionam, ainda, a percepção do público em relação ao comportamento corporativo como um fator de impacto em direção a uma economia de baixo carbono.

Segundo Jones \& Levy (2007), estratégias empresariais são movidas por percepções de interesse econômico, as quais são mediadas por diferentes cenários culturais, políticos e competitivos. Um entendimento acerca desses fatores é crucial para o desenvolvimento de uma combinação de políticas e ações capazes de promover a participação significativa e a redução substancial das emissões dos GEE.

O primeiro passo a ser tomado constitui-se na realização de um inventário acerca das emissões de GEE, identificando as fontes, tipos e magnitude das emissões. Em seguida, deve-se avaliar a vulnerabilidade dos processos de restrições de emissões de GEE. Três abordagens são comuns entre as empresas: 1) reduzir e/ou estabilizar as emissões de GEE; 2) reduzir o consumo de energia ou aprimorar a eficiência energética; e 3) reduzir somente o consumo de combustíveis fósseis (Kolk \& Pinkse, 2004).

Schultz \& Williamson (2005) destacam os benefícios da redução de custos e da diferenciação do produto ao integrar a oferta de créditos de carbono. Porter \& Reinhardt (2007) afirmam que as respostas estratégicas podem também envolver o desenvolvimento de um

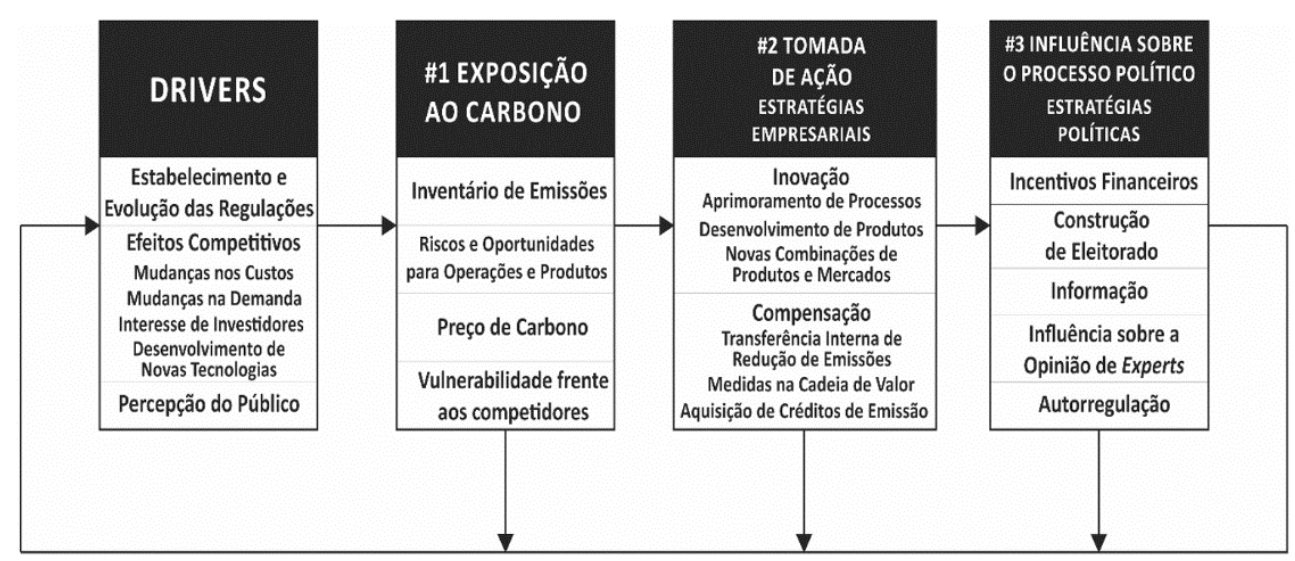

Figura 1. Framework teórico de definição de uma estratégia climática empresarial. Fonte: Elaborado com base em Kolk \& Pinkse (2004, 2005, 2007), Schultz \& Williamson (2005), Hoffman \& Woody (2008), Hillman \& Hitt (1999), e Bonardi \& Keim (2005). 
produto ou serviço, que se beneficiará da imagem de menos poluidor, ou até mesmo modificar e moldar regulações em seu benefício. Hoffman \& Woody (2008) afirmam que a empresa deve posicionar-se como um "comprador" ou "vendedor" nos mercados de carbono. Somente após compreender a vulnerabilidade e os impactos das emissões de GEE sobre sua cadeia de valor, os gestores serão capazes de elaborar um plano de ação.

Conforme afirmam Kolk \& Pinkse (2005), as empresas podem desenvolver estratégias com o foco em inovação ou apenas na compensação das emissões de GEE. A participação no comércio de emissões e de outras formas de offsets, como Mecanismos de Desenvolvimento Limpo e Implementações Conjuntas, configura-se como uma abordagem de compensação. Sob uma estratégia de compensação, os recursos tecnológicos e as competências de uma empresa permanecem praticamente inalterados.

Hoffman \& Woody (2008) afirmam que as empresas podem também participar do desenvolvimento de políticas públicas e influenciar o desenho de regulações. Kolk \& Pinkse (2007) afirmam que, em geral, esforços corporativos neste sentido ocorrem em países em que as restrições institucionais são mais frágeis. Em contrapartida, as estratégias de autorregulação, encaradas por Bonardi \& Keim (2005) como uma antecipação às demandas de grupos de interesse e ativistas, podem ser adotadas por multinacionais, independentemente do país sede.

De acordo com Kolk \& Pinkse (2007), estratégias climáticas podem envolver associações com organizações não governamentais $(\mathrm{ONG})$ ou participação em programas de governo. A associação com uma ONG integra, mais comumente, uma estratégia de resistência às demandas de ativistas ou de grupos de interesse. A participação em um programa do governo, normalmente, apresenta a intenção de prevenir futuras regulações e metas de redução de emissões de GEE. Southworth (2009) reforça, no entanto, que, na ausência de políticas públicas que imponham limites, as empresas não reduzirão as emissões de GEE. Os programas de ação voluntária configuram-se como uma solução incompleta e insuficiente para o problema das mudanças climáticas.

\section{Metodologia}

O estudo de caso múltiplo é de natureza qualitativa, descritiva e exploratória. As empresas estudadas configuram-se como líderes globais no fornecimento de bauxita, alumina e alumínio de alta qualidade. Mantêm operações de larga escala, eficientes, e de longa duração, empregando milhares de funcionários em diversos países. Foram estudadas uma multinacional anglo-australiana, a partir de sua subsidiária canadense (denominada de Empresa 1), e outra americana, a partir de sua subsidiária brasileira (denominada de Empresa 2).

Esta pesquisa envolveu três das seis fontes sugeridas por Yin (2010) para o desenvolvimento de um estudo de caso múltiplo: documentação, entrevistas e observações diretas. Utilizou-se a pesquisa documental de forma complementar, explorando informações contidas em documentos administrativos, artigos e notícias sobre as estratégias climáticas das empresas estudadas.

Empregou-se a técnica de entrevista em profundidade usando um instrumento de coleta de dados contendo questões que envolviam a percepção das empresas sobre a questão das mudanças climáticas; os principais drivers e os aspectos considerados relevantes na formulação estratégica; envolvendo os riscos e oportunidades para as operações. As entrevistas identificaram como as empresas realizam o inventário das emissões de GEE; como as mudanças climáticas afetam o posicionamento competitivo das empresas e qual a extensão das ações de inovação e compensação das emissões de GEE.

Com relação às estratégias políticas, as empresas foram questionadas sobre os principais stakeholders e como ocorre o relacionamento com o governo e a sociedade. Na ausência de restrições regulatórias, questionou-se se a empresa estava executando a autorregulação, quais as ações voluntárias e suas parcerias. Finalmente, foram identificadas como as soluções eram transferidas da matriz para as subsidiárias, e se elas eram obrigadas a seguir a estratégia climática da matriz ou se existia a possibilidade de adaptá-la ao contexto local. De modo inverso, as empresas foram questionadas se as subsidiárias influenciavam as estratégias climáticas globais da matriz.

As entrevistas foram realizadas em 2011, com funcionários diretamente envolvidos no processo de formulação das estratégias climáticas. No caso da empresa 1 (subsidiária canadense), as entrevistas foram realizadas em Montreal com o Diretor de Desenvolvimento de Negócios e Mudanças Climáticas (denominado de Entrevistado Can 1) e com o Conselheiro de Mudanças Climáticas (Entrevistado Can 2). No caso da empresa 2 (subsidiária brasileira), as entrevistas ocorreram com o Gerente de Saúde, Segurança e Meio Ambiente para a América Latina e Caribe (Entrevistado Bra 1) e com o Gerente local de Saúde, Segurança e Meio Ambiente (Entrevistado Bra 2) na planta da empresa em São Luís do Maranhão.

As quatro entrevistas tiveram em média uma duração de 60 minutos cada, tendo sido gravadas com a autorização prévia dos entrevistados. Cabe ressaltar que a área de mudanças climáticas é extremamente especializada nessas empresas e contam com um número mínimo de gestores. Esses se valem da estrutura de outras áreas para a realização de projetos de redução de emissões de GEE. Desta forma, a pesquisa contemplou os gestores que estavam 
realmente engajados com a definição de estratégias para resposta às mudanças climáticas. Como forma de proporcionar informação adicional sobre os tópicos estudados, as evidências observacionais ocorreram por meio de visita técnica às áreas produtivas nas duas empresas estudadas.

A partir das entrevistas semiestruturadas, da pesquisa documental e das observações, foi possível coletar os dados necessários, prezando pela convergência e encadeamento das evidências. As entrevistas foram transcritas e fez-se uso da lógica de combinação de padrão. Os dados coletados são comparados a um padrão previsto teoricamente, conforme orienta Godoy (2006), tendo por base as proposições teóricas estabelecidas na Figura 1. Desse modo, realizou-se o levantamento, organização e descrição das evidências significativas, encontradas a partir da coleta de dados.

Depois da condução independente dos dois estudos de caso, foi aplicada a técnica de síntese cruzada dos casos, recomendada por Yin (2010). Tal técnica envolve a criação de quadros que apresentam os dados dos casos individuais, de acordo com a estrutura das proposições teóricas estabelecidas, e a consequente comparação entre as empresas estudadas. A estratégia climática de cada empresa foi levantada e, em seguida, foram identificadas as similaridades e os contrastes existentes entre MNCs do setor de alumínio.

\section{Resultados}

\subsection{Estratégias climáticas adotadas no Canadá}

A Figura 2 sintetiza os principais elementos do processo de formulação das estratégias climáticas na empresa 1. Com relação aos drivers, os entrevistados relatam preocupação com a atuação do governo canadense, caso sejam estabelecidas metas compulsórias de redução de emissões de GEE. A empresa 1 iniciou o controle de suas emissões, reduzindo o consumo de energia, com impacto positivo em seus custos operacionais, para alcançar melhor posição competitiva.

Há uma combinação de avaliação de custos operacionais com a capacidade tecnológica, além do tempo hábil para atender à variedade de objetivos da empresa 1. A redução de emissões de GEE representa um entre tantos outros objetivos, como aumentar a produtividade e a segurança operacional, conforme relatam os entrevistados:

\begin{abstract}
Trata-se da combinação de vários aspectos, sendo uma questão de posicionamento estratégico para a empresa. Uma vez que mudanças climáticas possuem uma relação estreita com energia, tem-se um elemento estratégico. Energia é algo tão importante que não podemos não considerar apenas as políticas governamentais que possam afetá-la (Entrevistado Can 1). Não há receita mágica, não é assim tão fácil. Tudo é impulsionado pelo custo como em qualquer organização. Tudo o que se pode colocar em prática para reduzir os custos, melhorar a eficiência e levar a um melhor reconhecimento por parte dos governos, clientes e comunidades é válido (Entrevistado Can 2).
\end{abstract}

Os entrevistados caracterizam as relações com a comunidade como uma questão ética, além de mercadológica, o que indica que ocorrem pressões para um comportamento responsável. Contudo, constata-se fortemente a ênfase utilitarista no desempenho dos negócios, de acordo com o relato do entrevistado:

\begin{abstract}
Para com todos os drivers, deve haver um comprometimento. Algumas pessoas acreditam que nós devemos nos aprimorar, existindo um business case para aprimoramento, contudo como há pessoas envolvidas no negócio, então é mais do que um business case, digamos que é um caso ético (Entrevistado Can 2).
\end{abstract}

A empresa 1 implantou um sistema de gestão ambiental, que possibilitou a realização de um inventário confiável das emissões de GEE de todas as suas operações. Para tanto, atuou em parceria com agências do governo canadense e com organismos

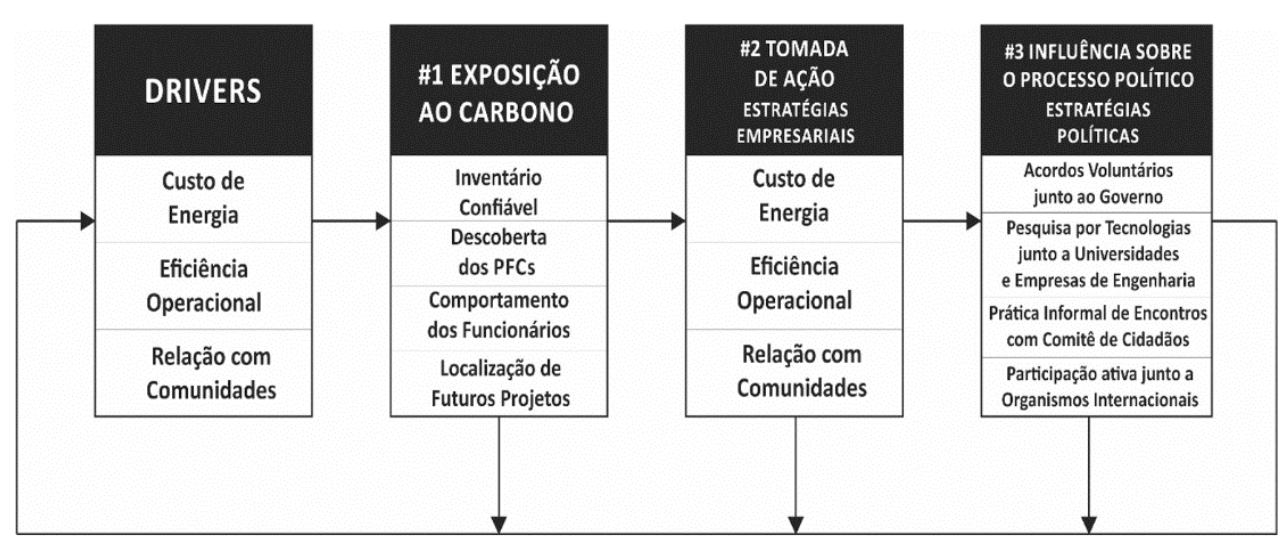

Figura 2. Estratégia Climática Adotada pela Empresa 1 no Canadá. Fonte: Elaborado pelos autores com base nas entrevistas. 
internacionais. Em seguida, desenvolveu, em seu próprio centro de pesquisa, tecnologias para mitigar as emissões. O engajamento com stakeholders, contribuiu, portanto, para a definição e padronização de parâmetros de mensuração das emissões de GEE, conforme relatos:

Qualquer redução que nós fizéssemos desse gás teria um grande impacto nas nossas emissões de GEE. Em razão de um melhor controle, nós já conseguimos reduzir quase que por completo as emissões de PFC e, assim, foi possível reduzir bruscamente nossas emissões de GEE, enquanto nossa produção continuou crescendo (Entrevistado Can 1). Nós obtivemos mais benefícios ao investir dinheiro em pesquisa, desenvolvendo novas tecnologias e aprimorando nossos recursos, do que participando em mercados de carbono. A tecnologia que exploramos hoje, já vinha sendo desenvolvida bem antes das mudanças climáticas. Contudo, somente após a descoberta do efeito anódico gerado pelos gases de PFC, é que nos atentamos para a questão das emissões (Entrevistado Can 2).

Do ponto de vista tecnológico, existem redes de P\&D ao redor do mundo, objetivando alcançar eficiência energética e a consequente redução das emissões de GEE. Conforme relata o entrevistado, há expectativas claras para cada subsidiária e há instruções sobre quais são as prioridades e os objetivos. No caso da força de trabalho, cada empregado realiza devidamente suas operações e conhece as demandas da comunidade e do governo, reunindo-se com eles regularmente, conforme relata:

Nós pensamos que as questões são mais bem resolvidas localmente por pessoas que conhecem os problemas e as preocupações. Obviamente as mudanças climáticas é uma questão global, mas que se traduz muito rapidamente em especificidades das comunidades e governos locais, logo, empregamos uma combinação de abordagens top-down e bottom-up (Entrevistado Can 1).

Quando questionados acerca do uso de mecanismos de compensação das emissões de GEE e a posição da empresa 1 nos mercados de carbono, os entrevistados reforçaram a posição de que "qualquer aspecto que afete os custos operacionais é uma grande questão a ser discutida". Observam-se também as incertezas regulatórias, com a proximidade do término da primeira fase do Protocolo de Kyoto e a posição ambígua do Canadá, para dificultar a tomada de decisões de investimentos, de acordo com o relato do entrevistado:

Carbono, preço de carbono, comércio de carbono, é como pôr em prática as ferramentas para controlar o jogo, mas você não sabe o que o jogo é ainda. Então, no início as concepções estavam ainda mal definidas. Para ser capaz de internalizar esses conceitos em nosso próprio negócio era muito difícil, por causa dessa indefinição, imprecisão (Entrevistado Can 1).
Outro aspecto que deve ser considerado no desenvolvimento de estratégias climáticas refere-se ao posicionamento da empresa em relação aos seus concorrentes. O desenvolvimento e a localização das plantas industriais tornaram-se, então, uma questão extremamente competitiva, de modo a garantir que o custo do controle das emissões de GEE não afetasse de forma significativa sua participação no mercado internacional.

Em razão do elevado impacto ambiental da produção de alumínio, o desempenho da empresa 1 sempre foi acompanhado de perto por agências reguladoras. Desse modo, mostrou-se natural que a empresa 1 interagisse com o governo canadense, havendo reuniões, troca de informações e trabalho colaborativo. O governo canadense, apesar de ter metas claramente definidas no Protocolo de Kyoto, não estabeleceu restrições de emissões de GEE que afetassem a indústria de alumínio. Os entrevistados reconhecem, no entanto, a necessidade de participação no processo político, conforme relata:

\begin{abstract}
Vendo de uma perspectiva mais ampla, nós trabalhamos e continuamos trabalhando com stakeholders de todos os tipos, mas certamente o governo é o número um para nós e, assim, desenvolvemos acordos voluntários junto aos mesmos, uma vez que há ausência de regulamentação e legislação. Pensamos que seria melhor para nós e para eles assinar algum tipo de compromisso para aprimorar nossas emissões, desse modo obtivemos o reconhecimento deles sobre o que estávamos fazendo, por buscar atribuir alguma certeza ao assunto (Entrevistado Can 2).
\end{abstract}

A empresa 1 participa ativamente junto a espaços de desenvolvimento político internacional, como a Asia Pacific Partnership, o International Energy Agency Coal Industry Advisory Board, o Coal Utilization Research Council, a CCS Association, o Carbon Disclosure Project, a US Climate Action Partnership (USCAP). Segundo os entrevistados, a estratégia é estar à frente no jogo e entender o que está por vir em dez ou vinte anos e como isso influencia o tipo de energia usado, o tipo de produto fabricado e a posição competitiva relativa a outros países, outras regiões e outros produtores de alumínio.

\subsection{Estratégias climáticas adotadas no Brasil}

As entrevistas revelaram que no ano de 2000, a empresa 2 lançou a estratégia para os próximos 20 anos ("Estratégia Global de Sustentabilidade 2020"), visando alcançar o tripé da sustentabilidade (econômico-ambiental-social) e incorporando a questão climática. O diagnóstico revelou que existia um gap entre o desempenho ambiental e as metas propostas na "Estratégia Global de Sustentabilidade 2020”. Foi montado, então, um novo Comitê Global 
de Sustentabilidade que desenvolveu um conjunto de metas para impulsionar o progresso de suas unidades até 2020 e, em algumas áreas, até 2030, o qual foi aprovado por seus executivos e líderes das unidades de negócio no início de 2010.

Desse modo, foram definidas, em 2007, metas para eficiência de energia, emissão de $\mathrm{CO}_{2}$, consumo de água, disposição de resíduos em aterros industriais, recuperação de áreas de mineração, e otimização de resíduos industriais. O parâmetro de referência dessas operações passou a ser a eficiência com que se utilizam os recursos, tendo a diretoria e o conselho de administração aprovado essa mudança para valores de intensidade, a partir de 2007. Conforme relato do entrevistado:

A empresa estabeleceu metas de onde ela queria estar em 20 anos: metas para eficiência de energia, emissão de $\mathrm{CO}_{2}$, consumo de água, disposição de resíduos em aterros industriais, recuperação de áreas de mineração, otimização de resíduos industriais, etc. E como ela foi pioneira, toda iniciativa pioneira tem o bônus de estar na vanguarda, mas tem o ônus de ter que se adequar à medida que o mundo também se adequa (Entrevistado Bra 1).

A Figura 3 sintetiza os principais elementos do processo de formulação das estratégias climáticas na empresa 2. Com relação aos drivers, os entrevistados destacam que foi determinante desenvolver bons relacionamentos com todos os stakeholders das localidades onde opera, incluindo os funcionários, sociedade, governo e ONGs. Essa rede de relacionamentos é encarada pela Empresa 2 como sua "licença para operar".

Quando questionados sobre o posicionamento da subsidiária frente aos concorrentes, os entrevistados afirmaram que a vantagem competitiva está em ir além do padrão e reduzir os custos operacionais. Contudo, não souberam apontar qual era a sua vantagem em relação aos seus concorrentes, afirmando que não há um parâmetro estabelecido, visto que se comparam processos, cubas, tecnologias e características diferentes.

Há um relacionamento de troca de informações entre as unidades, mas existe também um time líder de tecnologia de processos. Os entrevistados reforçam que há um engajamento geral com todos participando, em todas as áreas, não sendo apenas da gerência de meio ambiente. Os entrevistados relatam ainda que essa geração de conhecimento interna é compartilhada também por meio do IAI (International Aluminium Institute). O setor de alumínio, apesar de ser bastante competitivo, demonstra uma forte colaboração entre as empresas. Além disso, vista a atuação das plantas brasileiras como exportadoras, esse engajamento constitui uma questão de exigência do mercado e compromisso com os clientes.

As entrevistas revelaram que a empresa 2 realizou o inventário das emissões de GEE e definiu metas de redução. As metas de emissão de $\mathrm{CO}_{2}$ eram medidas em valores absolutos em cada unidade operacional. Contudo, estas metas passaram a ser medidas por quantidade de produto produzido, o que possibilita melhor avaliação da performance e comparações entre as unidades operacionais, conforme relato:

A redução que a gente tem hoje de fato palpável
é decorrente de um processo eletrolítico presente
na produção do alumínio. De uns 10 anos atrás até
hoje, foi-se capaz de reduzir bem acima de $50 \%$ das
emissões de GEE através desse processo. A indústria
do alumínio no mundo inteiro conseguiu reduzir
suas emissões de forma rápida, fácil e com relativo
baixo custo, e continuamos com essa medida, pois
acreditamos que há potencial para reduzir ainda
mais (Entrevistado Bra 2).

As mudanças operacionais incrementaram positivamente o monitoramento do desempenho da empresa 2, em termos de emissão de $\mathrm{CO}_{2}$ e eficiência energética. Em virtude do elevado custo de energia elétrica no Brasil, a empresa 2 passou a investir

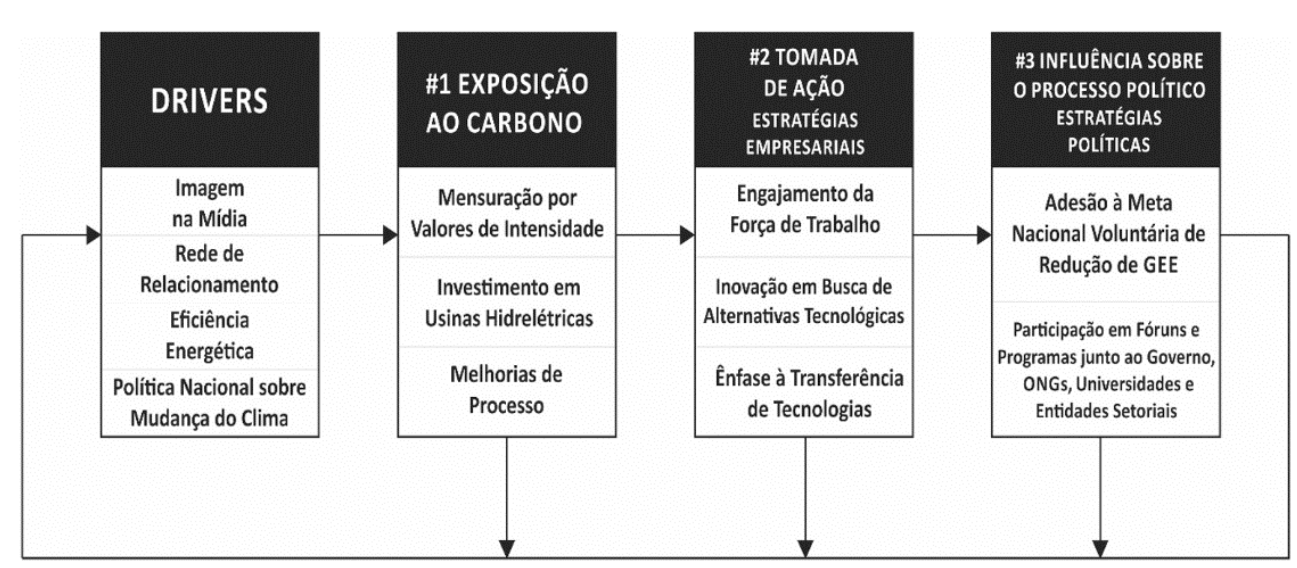

Figura 3. Estratégia Climática Adotada pela Empresa 2 no Brasil. Fonte: Elaborado pelos autores com base nas entrevistas. 
em usinas hidrelétricas e entrou em consórcios. A grande maioria dos investimentos realizados usa recursos próprios, com uma pequena parte advinda de instituições governamentais. $\mathrm{O}$ entrevistado complementa que está em fase de teste a substituição do óleo diesel queimado nos fornos por uma mistura de GNP (Gás Natural de Petróleo) com ar, o que resulta em um combustível denominado de flexgás. Desta forma, espera-se reduzir pelo menos $20 \%$ na geração de $\mathrm{CO}_{2}$, conforme relato:

\begin{abstract}
De 6 anos para cá, nós fizemos muitos estudos econômicos e técnicos para ver o que tínhamos de possibilidade. Nossa fábrica demanda muita energia, o processo de produção de alumínio consome muita energia elétrica, aí nós pensamos em garantir que a sua matriz seja a mais limpa possível, que seja hidrelétrica (Entrevistado Bra 2).
\end{abstract}

Também foram realizados testes em escala piloto, em termoelétricas usando biomassa oriunda do bagaço da cana-de-açúcar. A empresa 2 fez, ainda, outros estudos vinculados à energia eólica e energia solar. Uma oportunidade em que a Matriz tem apostado é a de sequestro de carbono, desenvolvida na Austrália em associação com outras empresas. O sequestro de carbono ocorre na lavagem do gás da chaminé com o resíduo cáustico da produção de alumínio. Tal medida tem gerado bons resultados, contudo, ainda é necessário acertar alguns problemas técnicos para que seja reproduzível em outras plantas industriais.

De acordo com os entrevistados, esta estratégia representa um modelo "ganha-ganha", no qual se tem dois problemas resolvidos ao mesmo tempo. O resíduo cáustico é neutralizado, ao mesmo tempo em que se deixa de gerar $\mathrm{CO}_{2}$. Já foram realizados testes no Brasil: em Poços de Caldas foram feitos testes usando $\mathrm{CO}_{2}$ industrial e em São Luís com água do mar. Como um exemplo de tecnologia gerada no Brasil e que foi compartilhado com as outras unidades, o entrevistado aponta o processamento de SPL (Spent Pot Lining), um revestimento gasto de cuba, que é um resíduo importante da fabricação de alumínio. Esta tecnologia foi apresentada pela empresa 2 para representantes da Matriz (Austrália) e de subsidiárias que operam na Europa e Estados Unidos.

Quanto à participação em mercados de carbono, os entrevistados alegam que a atuação ainda passa por uma fase de regulação, ora se fortalecem, ora se enfraquecem, sendo, assim, ainda muito instáveis e não são atraentes para investimentos. A empresa 2 considerou a possibilidade de desenvolver projetos de Créditos de Carbono junto ao MDL (Mecanismo de Desenvolvimento Limpo), definido pelo Protocolo de Kyoto. Contudo, a complexidade do processo de aprovação e registro, juntamente com a crise econômica de 2008, foram responsáveis por adiar esse intento.

Como a vigência do protocolo de Kyoto abrangeu o período de 2008 a 2012, os entrevistados tinham dúvidas com relação às mudanças na regulamentação internacional. Os entrevistados reforçam, no entanto, que independentemente dos desdobramentos futuros do protocolo, a empresa 2 tem intenção de continuar com projetos voluntários de autorregulação das emissões de GEE, conforme relata:

\begin{abstract}
As ações da empresa são basicamente voluntárias, até mesmo porque os Estados Unidos nunca quiseram assinar o Protocolo de Kyoto, tem-se, por exemplo, a Parceria Americana pela Ação Climática (United States Climate Action Partnership - USCAP), que é uma ação de líderes de mercado pressionando o governo americano por ações rápidas em relação ao aquecimento global (Entrevistado Bra 1).
\end{abstract}

As medidas de compensação das emissões de GEE representam um debate recente. A estratégia política adotada pela empresa 2 envolve o diálogo e a participação em fóruns no Brasil, como o Empresas pelo Clima promovido pela FGV (Fundação Getúlio Vargas), o Fórum Clima pelo Instituto Ethos e a Câmara Temática de Energia e Mudança do Clima pelo CEBDS (Conselho Empresarial Brasileiro pelo Desenvolvimento Sustentável). A empresa 2 participa, ainda, do Programa Brasileiro GHG Protocol, em parceria com a FGV, e do Inventário Nacional, em parceria com a Associação Brasileira do Alumínio (ABAL), para elaboração e divulgação de seus inventários de emissões de GEE. A empresa 2 tem se relacionado diretamente e por suas associações, como a ABAL, e, por meio desta, tem participado do Fórum Brasileiro sobre Mudanças Climáticas. Estas parcerias garantem a conferência e a confiabilidade dos dados publicados, conforme relata:

\begin{abstract}
A indústria está sendo chamada a debater qual vai ser a parte dela. Eu participei recentemente de dois eventos com o secretário Eduardo Assad e a própria Ministra Izabella Teixeira. A Confederação Nacional da Indústria (CNI) tem discutido bastante não só as questões climáticas, mas também sobre biodiversidade e uso de água. Nós temos participado via diversos fóruns e dialogado bastante com o governo e seus parceiros, então tem sido um diálogo aberto, em espaços bastante ativos, com as discussões ocorrendo quase toda semana (Entrevistado Bra 1).
\end{abstract}

Os entrevistados reforçam o fato de a sociedade brasileira ainda não entender o problema das mudanças climáticas. Contudo, acreditam que, com o aumento dos eventos climáticos extremos, haverá maior associação com as emissões de $\mathrm{CO}_{2}$ decorrentes das atividades industriais. Hoje ainda há muitas incertezas e muitos debates. 


\section{Discussão}

O estudo confirma que, tanto no Canadá quanto no Brasil, as corporações buscam estabelecer um consenso junto à sociedade acerca de sua legitimidade e responsabilidades envolvendo as emissões de gases do efeito estufa. Contudo, o ambiente institucional não se configura como um importante driver em ambos os casos pesquisados. As incertezas e indefinições sobre as metas de restrições das emissões de GEE e a evolução das regulações ainda caracterizam o cenário de políticas climáticas, tanto no Canadá quanto no Brasil. A ausência de restrições regulatórias leva as empresas a adotarem ações voluntárias de autorregulação, que não afetem os custos operacionais e a sua posição competitiva no mercado internacional.

Segundo Brouhle \& Harrington (2009), o Canadá caracteriza-se como um grande produtor de energia e um dos maiores emissores per capita de GEE, porém, não possui uma legislação que restrinja estas emissões. Incapaz de desenvolver um regime mandatório, o Canadá se apoia em uma abordagem voluntária. O governo canadense possui uma meta para redução de suas emissões até 2020 de 17\% abaixo dos níveis de 2005, a qual se alinha à meta dos Estados Unidos (Canada, 2010).

Este alinhamento destaca a situação de dependência vivida pelo Canadá e se dá em razão de os maiores riscos para a política climática canadense advirem das incertezas políticas dos Estados Unidos, complicando as decisões políticas em resposta às mudanças climáticas (Canada, 2011). Rivers (2010) afirma que esse retardamento para a implementação de políticas climáticas nos países desenvolvidos se deve a preocupações com a competitividade e a eficácia ambiental.

O Governo Brasileiro tem se voltado para as questões climáticas com a publicação da Política Nacional de Mudanças Climáticas. Rocha \& Rocha (2012) expõem que o País confirmou no Acordo de Copenhague, e na Conferência das Partes (COP16) em Cancun, as suas metas nacionais voluntárias de redução de emissões de GEE, entre 36,1\% e 38,9\% das emissões projetadas até 2020 (Brasil, 2009). A redução das emissões de GEE depende, fundamentalmente, da redução de desmatamento ilegal, de pastagens eficientes, e da questão de carvão vegetal para a siderurgia.

Viola \& Franchini (2013) defendem que a posição oficial do Brasil nas negociações sobre a mudança climática está influenciada por uma abordagem nacionalista/desenvolvimentista. No entanto, essa visão de mundo tem sido cada vez mais minada/permeada por outros atores estatais e não estatais, que são mais alinhados com as preocupações ambientais das partes interessadas internacionais. O conflito interno tem implicações importantes para a legitimidade e a coerência da posição brasileira nas negociações internacionais.

Na ausência de um eficiente ambiente regulatório, as características organizacionais das firmas assumem uma posição determinante para a adoção de estratégias climáticas. O Quadro 1 apresenta as abordagens das duas empresas pesquisadas, tomando por base as categorias definidas anteriormente no framework da pesquisa (Figura 1).

As duas MNCs destacam a grande relevância do fator custos para seus negócios e, por conseguinte, a necessidade de melhoria da eficiência operacional como os principais requisitos competitivos. O fator custos é decisivo no desenvolvimento de suas estratégias climáticas. Isso se deve ao desfavorável efeito da crise de 2008 sobre a rentabilidade da indústria do alumínio. As empresas passaram a ter dificuldades em controlar seus preços e reagiram ao aumento da concorrência internacional, concentrando-se na redução de custos e em maior eficiência, por meio de economias de escala, fusões, aquisições e melhorias tecnológicas (Figuerola-Ferretti, 2005).

Quadro 1. Visão comparativa da Estratégia Climática adotada por Multinacionais no Canadá (Empresa 1) e no Brasil (Empresa 2).

\begin{tabular}{|c|c|c|c|}
\hline \multirow{2}{*}{ CATEGORIAS } & \multirow{2}{*}{ DIMENSÕES } & \multicolumn{2}{|c|}{ MULTINACIONAL } \\
\cline { 2 - 3 } Forças Motrizes & Ambiente Regulatório & Dependente & EMPRESA 2 \\
\cline { 2 - 4 } & Requisitos Competitivos & Baseado em custos & Baseado em custos \\
\cline { 2 - 4 } & Pressão dos stakeholders & Perfil reativo & Perfil reativo \\
\hline \multirow{2}{*}{$\begin{array}{c}\text { Exposição ao } \\
\text { Carbono }\end{array}$} & Inventário & Controle interno & Controle interno \\
\cline { 2 - 4 } & Riscos x Oportunidades & $\begin{array}{c}\text { Oportunidade energética e } \\
\text { tecnológica }\end{array}$ & $\begin{array}{c}\text { Oportunidade energética e } \\
\text { tecnológica }\end{array}$ \\
\cline { 2 - 4 } & Mercado de Carbono & Ambiente desfavorável & Ambiente favorável \\
\hline $\begin{array}{c}\text { Estratégias } \\
\text { Empresariais }\end{array}$ & Compensação & Passivo & Ativo \\
\cline { 2 - 4 } \begin{tabular}{c} 
Estratégias Políticas \\
\cline { 2 - 3 }
\end{tabular} & Engajamento com stakeholders & Instrumental e Moral & Instrumental e Relacional \\
\cline { 2 - 4 } & Autorregulação & Princípio legal & Princípio relacional \\
\hline
\end{tabular}

Fonte: Elaborado pelos autores a partir dos dados coletados. 
Quanto à pressão dos stakeholders, a empresa 1 ressalta seu trabalho junto às agências governamentais canadenses e à comunidade, no intuito de formalizar seus relacionamentos e por perceber como salientes outros stakeholders que não a mídia. Enquanto a empresa 2 demonstra maior preocupação com sua imagem midiática. Em ambos os casos, as empresas possuem um perfil reativo, ou seja, respondem às demandas dos stakeholders.

Ambas as MNCs alegaram realizar inventário de suas emissões de GEE, como forma de melhor conhecer seu desempenho e, assim, ser capaz de controlar os riscos provenientes das suas operações. Percebe-se uma evolução do pensamento econômico que sai do foco único na análise de custo-benefício, passando a realizar também uma análise de risco inter e multidisciplinar. Este comportamento evidencia uma transição da tradicional abordagem de equilíbrio geral para uma compreensão adequada do comportamento nos níveis micro e macro (Barker, 2008).

A partir do inventário das emissões de GEE, as MNCs perceberam com maior clareza as oportunidades relacionadas com o processo de produção de alumínio. As medidas desenvolvidas para redução dos gases de PFCs colaboram não somente para a redução dos GEE como também para melhorias de eficiência dos processos (Rhoderick et al., 2001). Canadá e Brasil figuram entre os dez países que, no começo de 1999, empreenderam iniciativas conjuntas da indústria e do governo para reduzir as emissões de PFCs, a partir da produção primária do alumínio, desenvolvendo e dispondo de práticas e tecnologias que alcançaram expressivas reduções (EPA, 1999).

Em relação ao mercado de carbono, a empresa 2 apresenta uma visão mais otimista e maior disposição em se utilizar dos mecanismos de mercado, em oposição à postura cautelosa da empresa 1. Observa-se que a economia canadense é intensiva em energia, o que a torna especialmente suscetível à erosão da competitividade internacional pela imposição de tarifas para emissão de GEE (Rivers, 2010). Desse modo, o Canadá encara um ambiente desfavorável para seu posicionamento junto ao mercado de carbono. Ao contrário do Brasil, que apresenta uma situação favorável, justamente, por ser uma nação em desenvolvimento, figurando como destino para transferência de tecnologias e investimentos, sem uma meta compulsória internacional de redução de GEE a cumprir.

Em decorrência desse cenário, ao traçar suas estratégias climáticas, a empresa 1 assume uma posição passiva em relação a ações de compensação das emissões de GEE, acompanhando as discussões relacionadas e as práticas de outras empresas sem, contudo, apresentar estímulos suficientes para internalizá-las ao seu negócio. Por outro lado, a empresa 2 se mostra ativa ao avaliar positivamente a possibilidade de implementar projetos de Mecanismo de Desenvolvimento Limpo (MDL) em suas instalações.

Considerando os riscos e oportunidades específicos da indústria de alumínio, ambas multinacionais decidiram dar prioridade a iniciativas inovadoras de $\mathrm{P} \& \mathrm{D}$, ao invés de explorarem abordagens de compensação das emissões de GEE. Tecnologias alternativas, fontes de energia mais limpas e treinamento da força de trabalho constituem as principais estratégias desenvolvidas. A empresa 1 mostra-se inovadora e enfatiza o desenvolvimento de know-how, objetivando não apenas implementá-lo em suas instalações e propagá-lo entre as outras subsidiárias, como também vendê-lo a outras empresas (Gupta \& Govindarajan, 1991).

A empresa 2 enfatiza a intensa troca de informações com as outras subsidiárias instaladas em outros países. Contudo, não possui centros de tecnologias instalados no Brasil, figurando-se como uma implementadora dos avanços tecnológicos desenvolvidos fora de suas instalações (Gupta \& Govindarajan, 1991). Para Mudambi \& Navarra (2004), as subsidiárias que controlam parte significativa dos recursos de P\&D detêm os bens mais preciosos da firma, possuindo um alto poder de barganha dentro da multinacional.

No exercício de estratégias políticas, as duas MNCs mostram-se claramente motivadas a se engajar com seus stakeholders por razões instrumentais, ou seja, impulsionadas por interesse próprio, visando obter vantagem competitiva e/ou evitar desvantagens. Além disso, ao encarar as questões climáticas como um caso ético, e não apenas como um business case, a empresa 1 apresenta uma base moral, refletindo uma preocupação ética com o bem-estar de seus stakeholders. A empresa 2, ao se comunicar e se articular com diversos atores, apresenta uma base relacional, conforme definido por Aguilera et al. (2006), refletindo uma preocupação com sua situação e posição junto a seus stakeholders.

Não existe uma lógica enraizada no Canadá que justifique o uso de estratégias de negociação eticamente inadequadas, apresentando, assim, esse país um alto padrão moral em negociações comerciais (Ma, 2010). Segundo Volkema \& Fleury (2002), enquanto a cultura, sem dúvida, desempenha um papel importante em determinar se os negociadores vão empregar ou não táticas questionáveis ou antiéticas, ela sozinha não determina atitudes, intenções e ações. As condições econômicas também podem influenciar esse comportamento. Estes autores afirmam ainda que, no Brasil, encontrar maneiras de contornar os trâmites burocráticos de uma cultura de alta aversão à incerteza muitas vezes envolve o uso de uma estendida rede social.

Quanto às estratégias políticas, a de autorregulação aparece como majoritariamente empregada pelas duas MNCs. Porém, ao ter o governo como seu principal stakeholder, a empresa 1 demonstra possuir um 
princípio legal, priorizando a formalização de acordos voluntários junto a agências governamentais. Por outro lado, a empresa 2 demonstra possuir um princípio muito mais relacional, optando por traçar acordos voluntários junto a diversas instituições, dentre elas ONGs, associações da indústria e o próprio governo.

North (1990) assinalou que os países desenvolvidos são fortemente dependentes de regras formais e menos dependentes de restrições informais. Svensson et al. (2009) constataram que o Canadá apresenta um alto nível de normas formais estabelecidas, estando suas empresas sujeitas a um sistema mais regrado. Schmidheiny (2006) salientou que o engajamento social reforça a identificação das empresas brasileiras como "uma contribuição significativa para a solução dos problemas sociais do país". Abreu \& Barlow (2013) reforçam a identificação de empresas líderes no Brasil com atividades discricionárias e a adoção de um perfil instrumental e relacional.

\section{Conclusão}

O trabalho traça um framework capaz de orientar estudos sobre estratégias climáticas. A fase inicial consiste em uma avaliação dos drivers (forças motrizes) envolvendo as exigências regulatórias, o comportamento dos competidores e as exigências dos stakeholders. Este processo conduz a uma identificação da "exposição ao carbono", à qual as empresas aliam o conhecimento das pressões externas com o potencial de emissão de GEE. Ao traçarem seus inventários de emissões de GEE, as empresas são capazes de avaliar os riscos e as oportunidades relacionados com a mudança climática. Em seguida, as empresas podem realizar a "tomada de ação" e exercer "influência sobre o processo político".

A pesquisa demonstra que, em nenhum dos casos estudados, as exigências regulatórias figuram como fator determinante na definição de estratégias climáticas. Fica clara a dificuldade de se lidar com um cenário de incertezas, marcado por intensas discussões e raras definições. A pesquisa revela que atuam como drivers as pressões internas do ambiente organizacional e as demandas do mercado internacional, com ênfase na identificação do comportamento dos competidores. Estes fatores organizacionais, característicos da firma, apresentam-se mais significativos que as pressões institucionais coercitivas do Canadá ou Brasil. Conforme enfatiza Lee (2012), ações de longo prazo capazes de reduzir os riscos da mudança climática exigem incentivos econômicos explícitos e ações governamentais.

A capacidade tecnológica da indústria de alumínio é um reflexo de investimentos com foco na redução de custos e a melhoria na eficiência operacional, com efeitos secundários na redução de emissões de GEE. As empresas pesquisadas não exploram abordagens de compensação com investimentos em projetos de Mecanismo de Desenvolvimento Limpo (MDL). Aliadas às ações de inovação tecnológica, desenvolvem estratégias políticas, destacando-se a parceria com agências governamentais, organismos internacionais, ONGs e institutos de pesquisa.

Os resultados desta pesquisa corroboram outros achados. Por exemplo, Weinhofer \& Busch (2013) demonstraram que capacidade de antecipação e de gerenciamento dos riscos da mudança climática depende dos diferentes níveis de conhecimento sobre os impactos causados. Os autores defendem que a adaptação organizacional às mudanças climáticas exige adoção de uma perspectiva contingencial. As firmas necessitam conhecer as mudanças no ambiente externo e procurar recursos internos para se adaptar.

Galbreath (2014) reforça a existência de trade-offs normativos e instrumentais no comprometimento dos recursos da firma em ações mitigadoras e adaptativas às mudanças climáticas. As empresas se comportam de forma hesitante nos investimentos de recursos escassos, para se adaptarem à mudança climática, na ausência de uma demanda do mercado e de pressões regulatórias ou uma clara identificação de benefícios econômicos e na imagem da firma.

Este estudo não é, todavia, sem limitações. Primeiro, ele se baseia no autorrelato de informações fornecidas pelos gestores, contudo a pesquisa também se apoia no uso conjunto de documentos e observações para verificar os resultados das entrevistas. Outra limitação refere-se ao número de entrevistados, embora, conforme observado na seção de metodologia, sejam os gestores que trabalham e representam as áreas que desenvolvem as estratégias climáticas.

Apesar dessas limitações, o estudo sinaliza uma configuração de respostas estratégicas às mudanças climáticas e demonstra a importância das especificidades das estruturas organizacionais. A adoção de estratégias de adaptação às mudanças climáticas pode ser capaz de criar organizações inovadoras, robustas e resilientes, para avançarem em um ambiente de incertezas associadas com a severidade, escala e escopo dos impactos.

\section{Agradecimentos}

Ao $\mathrm{CNPq}$ pelo apoio financeiro ao Projeto de Pesquisa e ao CBIE (Canadian Bureau for International Education) pela bolsa de estudos na HEC-Montreal. Ao editor e aos revisores anônimos por suas contribuições para melhoria da versão inicial deste artigo.

\section{Referências}

Abreu, M. C. S., \& Barlow, C. (2013). A comparative picture of corporate social responsibility approaches by leading companies in the United Kingdom and Brazil'. Social Responsibility Journal, 9(4), 571-588. http:// dx.doi.org/10.1108/SRJ-04-2012-0046. 
Aguilera, R. V., Williams, C. A., Conley, J. M., \& Rupp, D. E. (2006). Corporate Governance and Social responsibility: a comparative analysis of the UK and the US. Corporate Governance and Social Responsibility, 14(3), 147-158. http://dx.doi.org/10.1111/j.1467-8683.2006.00495.x.

Barker, T. (2008). The economics of avoiding dangerous climate change: an editorial essay on The Stern Review. Climatic Change, 89(3-4), 173-194. http://dx.doi. org/10.1007/s10584-008-9433-x.

Bonardi, J.-P., \& Keim, G. D. (2005). Corporate political strategies for widely salient issues. Academy of Management Review, 30(3), 555-576. http://dx.doi. org/10.5465/AMR.2005.17293705.

Brasil. (2009, 29 de dezembro). Lei $n .^{\circ}$ 12.187, de 29 de dezembro de 2009. Institui a Política Nacional sobre Mudança do Clima - PNMC e dá outras providências. Brasília, DF: Diário Oficial da República Federativa do Brasil. Recuperado em 26 de janeiro de 2012, de http:// www.planalto.gov.br/ccivil_03/_ato2007-2010/2009/ lei/112187.htm.

Brouhle, K., \& Harrington, D. R. (2009). Firm strategy and the canadian voluntary Climate Challenge and Registry (VCR). Business Strategy and the Environment, 18(6), 360-379. http://dx.doi.org/10.1002/bse.604.

Canada. Government of Canada. (2010, 26 de novembro). Canada's action on climate change fact sheet. Recuperado em 26 de janeiro de 2012, de http://climatechange.gc.ca/ default.asp?lang=En\&n=D43918F1-1.

Canada. Government of Canada. National Round Table on the Environment and the Economy. (2011). Parallel Paths: Canada-U.S. Climate Policy Choices. Ottawa: NRTEE. Recuperado em 26 de janeiro de 2012, de http://nrtee-trnee.ca/wp-content/uploads/2011/08/ canada-us-report-eng.pdf.

Dando, N. R., Sylvain, L., Fleckenstein, J., Kato, C., Van Son, V., \& Coleman, L. (2011). Sustainable anode effect based perfluorocarbon emission reduction. In J. S. Lindsay (Ed.), Light Metals 2011 (pp. 325328). New Jersey: John Wiley \& Sons.. http://dx.doi. org/10.1002/9781118061992.ch58.

Ellis, K. M. (2000). Strategic contexts, knowledge flows, and the competitiveness of MNCs: a procedural justice approach. Competitiveness Review, 10(1), 9-24. http:// dx.doi.org/10.1108/eb046386.

Figuerola-Ferretti, I. (2005). Prices and production cost in aluminium smelting in the short and the long run. Applied Economics, 37(8), 917-928. http://dx.doi. org/10.1080/00036840500061244.

Freitas, A. R. P., Abreu, M. C. S., \& Albuquerque, A. M. (2013). Implicações estratégicas de projetos de mecanismos de desenvolvimento limpo em empresas de energia renovável. Revista Sistema \& Gestão, 8(4), 334-345. http://dx.doi.org/10.7177/sg.2013.v8.n4.a2.

Fujiwara, N., \& Egenhofer, C. (2008). Global Sectoral Industry Approaches to Climate Change: The Way Forward. Brussels: Centre for European Policy Studies. CEPS Task Force Reports. Recuperado em 21 de julho de 2011, de http://www.ceps.be/book/global-sectoralindustry-approaches-climate-change-way-forward.

Galbreath, J. (2014). Climate change response: evidence from the margaret river wine region of Australia. Business Strategy and the Environment, 23(2), 89-104. http://dx.doi.org/10.1002/bse.1762.

Global Humanitarian Forum - GHF. (2009). Human Impact Report: climate change. The anatomy of a silent crisis. Genebra. Recuperado em 19 de setembro de 2010, de http://www.preventionweb.net/files/9668 humanimpactreport1.pdf.

Godoy, A. S. (2006). Estudo de caso qualitativo. In C. K. Godoi, R. Bandeira-de-Mello \& A. B. Silva (Orgs.), Pesquisa qualitativa em estudos organizacionais: paradigmas, estratégias e métodos. São Paulo: Saraiva.

Gupta, A. K.; \& Govindarajan, V. (1991). Knowledge flows and the structure of control within multinational corporations. Academy of Management Review, 16(4), 768-792.

Harrison, E. B. (2009). Corporate Greening 2.0: factors in play as executives zero in on climate change. Corporate Communications: An International Journal, 14(3), 280285. http://dx.doi.org/10.1108/13563280910980069.

Hillman, A. J., \& Hitt, M. A. (1999). Corporate Political Strategy Formulation: a model of approach, participation, and strategy decisions. Academy of Management Review, 24(4), 825-842.

Hoffman, A. J. (2007). The coming market shift: Climate change and business strategy. In K. Tang \& R. Yoeh (Eds.), Cut carbon, grow profits: business strategies for managing climate change and sustainability (pp. 101-118). London: Middlesex University Press.

Hoffman, A. J., \& Woody, J. G. (2008). Climate change: what's your business strategy? Boston: Harvard Business School Publishing Corporation.

Intergovernmental Panel on Climate Change - IPCC. (2013). Climate Change 2013: the physical science basis (Working Group I Contribution to the Fifth Assessment Report of the Intergovernmental Panel on Climate Change). Cambridge: Cambridge University Press. 1535 p.

Jones, C. A., \& Levy, D. L. (2007). North american business strategies towards climate change. European Management Journal, 25(6), 428-440. http://dx.doi. org/10.1016/j.emj.2007.07.001.

Kolk, A., \& Levy, D. (2004). Multinationals and global climate change: issues for the automotive and oil industries. In S. Lundan, S. (Ed.), Multinationals, environment and global competition (Research in Global Strategic Management, Vol. 9, pp. 171-193). Oxford: Elsevier.

Kolk, A., \& Pinkse, J. (2004). Market strategies for climate change. European Management Journal, 22(3), 304-314. http://dx.doi.org/10.1016/j.emj.2004.04.011.

Kolk, A., \& Pinkse, J. (2005). Business responses to climate change: identifying emergent strategies. 
California Management Review, 47(3), 6-20. http:// dx.doi.org/10.2307/41166304.

Kolk, A., \& Pinkse, J. (2007). Multinational's political activities on climate change. Business \& Society, 46(2), 201-228. http://dx.doi.org/10.1177/0007650307301383.

Kolk, A., \& Van Tulder, R. (2010). International business, corporate social responsibility and sustainable development. International Business Review, 19(2), 119-125. http:// dx.doi.org/10.1016/j.ibusrev.2009.12.003.

Kolk, A. (2008). Developments in corporate responses to climate change within the past decade. In H. Bernd \& A. Ralf(Eds.), Economics and management of climate change (pp. 221-230). New York: Springer.. http:// dx.doi.org/10.1007/978-0-387-77353-7_16.

Lash, J., \& Wellington, F. (2007). Competitive advantage on a warming planet. Harvard Business Review, 85(3), 94-102, 143. PMid:17348173.

Lee, S. Y. (2012). Corporate carbon strategies in responding to climate change. Business Strategy and the Environment, 21(1), 33-48. http://dx.doi.org/10.1002/bse.711.

Ma, Z. (2010). The SINS in business negotiations: explore the cross-cultural differences in business ethics between Canada and China. Journal of Business Ethics, 91(S1), 123-135. http://dx.doi.org/10.1007/s10551-010-0571-5.

Mudambi, R., \& Navarra, P. (2004). Is knowledge power? Knowledge flows, subsidiary power and rent-seeking within MNCs. Journal of International Business Studies, 35(5), 385-406. http://dx.doi.org/10.1057/palgrave. jibs. 8400093 .

North, D. (1990). Institutions, institutional change and economic performance. Cambridge: Cambridge University Press.. http://dx.doi.org/10.1017/CBO9780511808678.

Okereke, C. (2007). An exploration of motivations, drivers and barriers to carbon management: the UK FTSE 100. European Management Journal, 25(6), 475-486. http:// dx.doi.org/10.1016/j.emj.2007.08.002.

Porter, M. E., \& Reinhardt, F. L. (2007). Grist: a strategic approach to climate. Harvard Business Review, 85(10), 22-26.

Reinhardt, F. L. (2007). Opinion: place your bets on the future you want. Harvard Business Review, 85(10), 42-43.

Rhoderick, G., Chu, P., Dolin, E., Marks, J., Howard, T., Lytle, M., McKenzie, L., \& Altman, D. (2001). Development of perfluorocarbon (PFC) primary standards for monitoring of emissions from aluminum production. Fresenius' Journal of Analytical Chemistry, 370(7), 828-833. http://dx.doi.org/10.1007/s002160100883. PMid:11569859.

Rivers, N. (2010). Impacts of climate policy on the competitiveness of Canadian industry: how big and how to mitigate? Energy Economics, 32(5), 1092-1104. http://dx.doi.org/10.1016/j.eneco.2010.01.003.
Rocha, T. F., \& Rocha, D. G. M. (2012). Ciência e política nas convenções do clima da ONU. Revista VITAS: Visões Transdisciplinares sobre Ambiente e Sociedade, (3).

Rosen, C. M. (2007). Doing business history in the age of global climate change. Enterprise and Society, 8(2), 221-226. http://dx.doi.org/10.1093/es/khm028.

Schmidheiny, S. (2006). A view of corporate citizenship in latin america. Journal of Corporate Citizenship, 2006(21), 21-24. http://dx.doi.org/10.9774/GLEAF.4700.2006. sp.00004.

Schultz, K., \& Williamson, P. (2005). Gaining competitive advantage in a carbon-constrained world: strategies for european business. European Management Journal, 23(4), 383-391. http://dx.doi.org/10.1016/j.emj.2005.06.010.

Seiffert, M. E. B. (2009). Mercado de carbono e Protocolo de Quioto: oportunidades de negócio na busca de sustentabilidade. São Paulo: Atlas.

Southworth, K. (2009). Corporate voluntary action: a valuable but incomplete solution to climate change and energy security challenges. Policy and Society, 27(4), 329-350. http://dx.doi.org/10.1016/j.polsoc.2009.01.008.

Svensson, G., Wood, G., Singh, J., Carasco, E., \& Callaghan, M. (2009). Ethical structures and processes of corporations operating in Australia, Canada, and Sweden: a longitudinal and cross-cultural study. Journal of Business Ethics, 86(4), 485-506. http://dx.doi. org/10.1007/s10551-008-9860-7.

The World Business Council for Sustainable Development - WBCSD. (2005). Pathways to 2050: energy and climate change. Switzerland: Atar Roto Presse SA. Recuperado em 17 de Abril de 2011, de http://www. wbcsd.org/web/publications/pathways.pdf.

United States Environmental Protection Agency - EPA. (1999). EPA 430-R-99-001: International Efforts to Reduce Perfluorcarbon (PFC) Emissions from Primary Aluminium Production. Air and Radiation (6202J). Recuperado em 26 de janeiro de 2012, de http://nepis. epa.gov/EPA/html/DLwait.htm?url=/Adobe/PDF/ P1000MLD.PDF.

Viola, E., \& Franchini, M. (2013). Brasil na Governança Global do Clima, 2005-2012: a luta entre conservadores e reformistas. Contexto Internacional, 35(1), 43-76.

Volkema, R. J., \& Fleury, M. T. L. (2002). Alternative negotiating conditions and the choice of negotiation tactics: a crosscultural comparison. Journal of Business Ethics, 36(4), 381-398. http://dx.doi.org/10.1023/A:1014496017565.

Weinhofer, G., \& Busch, T. (2013). Corporate strategies for managing climate risk. Business Strategy and the Environment, 22(2), 121-144. http://dx.doi.org/10.10002/ bse. 1744 .

Yin, R. K. (2010). Estudo de caso (4. ed.). Porto Alegre: Bookman. 